\title{
Collaborative effect of workplace ostracism and self-efficacy versus job stress
}

\section{Ambreen Sarwar ${ }^{1}$ iD, Muhammad Ibrahim Abdullah ${ }^{2}$ Muddassar Sarfraz ${ }^{3}$ iD, Muhammad Kashif Imran 4}

\begin{abstract}
This paper aims to illuminate the association between workplace ostracism and stress since ostracism is the most prevalent form of mistreatment in modernday work settings. The study also investigates the moderating role of employees' self-efficacy, gender, and work culture. Data was collected through a survey and structured questionnaires from employees working in both public and private sector banks in Pakistan. Data Analysis was conducted using statistical techniques such as bootstrapping, regression analysis and process macros. The study findings reveal that workplace ostracism is positively related to stress; and negatively related to employee's self-efficacy. Gender and organizational work culture have a moderating relationship. Self-efficacy mitigated the adverse effects of workplace ostracism in the form of stress, as self-efficacious employees tend to experience less stress in their workplace. Organizations must take account of the stress-mitigating impact of self-efficacy which is principally strong for producing acceptable performance since mistreatment and impolite behaviors cannot be evaded and prevented entirely in the social context of the contemporary workplace. Implications and future research directions are discussed in light of the findings.
\end{abstract}

Keywords: workplace ostracism, stress, self-efficacy, conservation of resources theory, banking industry, Pakistan, Punjab

\footnotetext{
1 Ambreen Sarwar, Ph.D. student at Department of Management Sciences, Comsats University Islamabad, Lahore Campus, 1.5 KM Defense Road، Off Raiwand Rd, Pakistan, email: ambreen_sarwar@hotmail.com (ORCID ID: 0000-0002-5379-4049). 2 Muhammad Ibrahim Abdullah, Ph.D., Assistant Professor, Department of Management Sciences, Comsats University Islamabad, Lahore Campus, 1.5 KM Defense Road, Off Raiwand, Pakistan 54000, email: miabdullah@cuilahore.edu.pk (ORCID ID 0000-0001-8741-9952).

3 Muddassar Sarfraz, Ph.D., Postdoctoral Fellow, Department of Management and HR, Business School, Hohai University, Focheng Road Nanjing, Jiangsu, PR China 211100, email: muddassar@hhu.edu.cn (ORCID ID: 0000-0001-6165-732X). 4 Muhammad Kashif Imran, Ph.D. student at Department of Management Sciences, The Islamia University of Bahawalpur, University Chowk, Bahawalpur, Pakistan 63100, email: kkaasshhii@gmail.com (ORCID ID: 0000-0002-2030-922X).
} 


\section{INTRODUCTION}

Workplaces are sites embodying specific regulations deemed as suitable in a particular society (Di Marco, Martinez-Corts, Arenas, \& Gamero, 2018). Often, these regulations might be disregarded by employees as they engage in behaviors viewed as deviant at that instance and in that setting (Pawar, 2013), influencing their wellbeing, satisfaction (Di Marco, Martinez-Corts, Arenas, \& Gamero, 2018) and workplace social context (Chung, 2018). Such social context has substantial importance in modern-day work settings since employees spend a significant amount of time with each other at work (Chung, 2018). Unfortunately, workplace social context has been increasingly characterized by negative attitudes and behaviors including various forms of mistreatment and victimization (Aquino \& Thau, 2009) like incivility (Di Marco et al., 2018; Abubakar, Yazdian, \& Behravesh, 2018) social undermining (Duffy, Ganster, \& Pagon, 2002), harassment, bullying (Einarsen, 2000), and abusive supervision (Tepper, 2000). One of the most prevalent of these is workplace ostracism (Fox \& Stallworth, 2005; as cited by Steinbauer, Renn, Chen, \& Rhew, 2018).

Regrettably, it is one of the neglected areas in the literature, especially in developing nations that perhaps might serve as a crucial determinant of negative mental states of personnel in the workplace, resulting in harmful behaviors. When personnel comes across verbal abuse, rude or indecorous behavior, or unfair burden in the workplace, mistreatment arises (Abubakar, Yazdian, \& Behravesh, 2018; McCord, Joseph, Dhanani, \& Beus, 2018).

Some recent studies on mistreatment have tried to shed light on its harmful influences on employees' physical and mental health (Harnois \& Bastos, 2018), turnover intentions (Chaudhry, Mahesar, Pathan, Arshad, \& Butt, 2017; Lyu \& Zhu, 2017) and interpersonal deviance (Jahanzeb \& Fatima, 2017) among others. Mistreatment gives a feeling of social rejection and exclusion to the employees, which might hamper their capacity to contribute positively towards the achievement of organizational goals (Abubakar, Yazdian, \& Behravesh, 2018).

Since ostracism is found to be most prevalent in workplaces (Fox \& Stallworth, 2005; as cited by Steinbauer, Renn, Chen, \& Rhew, 2018), the focus of the current study is this kind of covert mistreatment, prevailing in the banking industry of a developing nation, Pakistan, where legislation regarding workplace mistreatment is rather weak. A couple of relatively recent studies show that most of the surveyed employees had sensed workplace ostracism (WPO) at one time or another during their work course (Fox \& Stallworth, 2005; O'Reilly, Robinson, Berdahl, \& Banki, 2014). Unfortunately, companies do not generally regard WPO as liable to be punished as it is usually considered as a passive form of mistreatment (Abubakar, Yazdian, \& Behravesh, 2018; O'Reilly et al., 2014). 
Conservation of resources (COR) theory offers an insightful perspective to comprehend the impact of WPO. WPO depletes valuable resources which are vital to assist personnel in the workplace (Leung, Wu, Chen, \& Young 2011). In such a situation, a person's defense mechanism might be triggered. In an attempt at protecting against additional resource loss, personnel might face continuous stress and go through more resource deficit, resulting in a range of adverse work-related outcomes.

According to Hobfoll, Halbesleben, Neveu, and Westman (2018), COR theory starts with the precept that people attempt to gain, retain, foster, and protect the possessions they centrally value. Among these commonly valued resources are health, sense of belongingness, well-being, family, self-esteem, and a sense of purpose and meaning in life. The degree of belongingness, social controls, self-esteem, and meaningful existence determine the level of individuals' personal and social resources. The threat to these resources may result in a tend-and-befriend reaction (Williams, 2007) and results in stress (Hobfoll et al., 2018). Additionally, in the premises of COR theory, personal, situational and other positive resources like self-control and self-belief might prove helpful in mitigating the adverse effect of resource loss that might ultimately be translated into poor performance.

WPO has been implied to be an interpersonal stressor (Williams, 1997; 2001; Jahanzeb \& Fatima, 2017); nonetheless, researchers have seldom examined WPO from a stress standpoint (Chung, 2018) in a developing country. According to Wu Yim, Kwan, and Zhang (2012), it is imperative to examine the association between WPO and stress-related outcomes. Hence, the current study will investigate the association between WPO and stress in the non-western context of Pakistan, specifically in the banking industry, where jobs are characterized as one of the most stressful ones in Pakistan (Badar, 2011; Khattak, Khan, Haq, Arif, \& Minhas, 2011).

Banking staff from junior to the most senior levels are involved in providing customer services and have frequent interactions with customers on a daily basis (Khattak et al., 2011). The daily customer turn-up in this industry is high (Badar, 2011), when compared to other service-related industries, since people in Pakistan must usually visit their bank for any financial transaction related to cash, cheques, paying bills, demand drafts, account statements, and other queries. Also, the task inter-dependence of banking colleagues is on the higher side. Employees must interact with each other, management, peers and colleagues frequently to complete customer-related tasks (Badar, 2011). According to Aquino \& Thau's (2009) prediction, employees can expect to be a victim of workplace mistreatment when it is vital for them to interact with each other more often and to work interdependently. Such high task interdependence may transmute into 
magnified adverse impacts of workplace ostracism, and consequently, such effects will shift towards bankers' services to customers. It is also important to note that the work culture, context, and processes in the public versus private sector in Pakistan are noticeably different (Rashid \& Rashid, 2012; Khan, Safwan, \& Ahmad, 2011; Khan, Aslam, \& Riaz, 2012), and therefore the intensity and effects of mistreatment in these sectors might be different.

Interestingly, extant literature has shown mixed results between various forms of mistreatment and their effects between the genders (e.g., see Aquino \& Thau, 2009). Women are also found to sense more stress, anxiety, and distress. According to the American Psychiatric Association (2000), females are more frequently diagnosed with general anxiety as compared to males. The banking sector in Pakistan, characterized as stressful (Badar, 2011), means higher stress levels for women as compared to men. Since women are found to be more relationship-oriented and attain a sense of identity through affiliation, depicting themselves using relational terms, such as "giving", "helping", "caring", "being kind", and "not hurting others" (Gilligan, 1982); it is expected that the negative influence of mistreatment on women, in the form of stress, might be more nuanced comparative to men. The early socialization theory attributes such differences in value orientation, as internalized through the early socialization process. The theory emphasizes that regardless of social changes, gender remains an elementary social category that outlines a person's values, perceptions, work-related outlook and behaviors (Danziger \& Eden, 2007). Studying the effect of gender, in ostracism, stress relationships, in Pakistan would be an added contribution to the literature.

Furthermore, there are calls for identifying various boundary conditions (Chung, 2018; Lyu \& Zhu, 2017; Abubakar, Yazdian, \& Behravesh, 2018; Zhu, Lyu, Deng, \& Ye 2017) that might mitigate or exacerbate adverse effects of ostracism, by applying theories other than job embeddedness (Lyu \& Zhu, 2017) in the service sector (e.g. banking, hospitality and others) of a developing country (Abubakar, Yazdian, \& Behravesh, 2018) since they are underexplored (Chung, 2018). Based on conservation of resources theory (COR) (Hobfoll, 1989) and answering to the call of Abubakar, Yazdian and Behravesh, (2018) to include psychological capital as a boundary condition in the form of a personal factor, the present research argues that self-efficacy (SE) (a person's primary belief in his or her capabilities and control over outside events), would serve as a mitigating agent and buffer the detrimental influence of workplace ostracism on stress in the banking industry in Pakistan.

Moreover, this study offers an exciting social, in addition to institutional, counterpoint to the leading Western (mainly US and UK) based researches (Quratulain, Khan, Crawshaw, Arain, \& Hameed, 2016) of workplace illtreatment (e.g., Steinbauer et al., 2018). Pakistani culture, being relatively high 
in power distance, collectivism and uncertainty avoidance, points to a society with a high rule orientation, and support to high disparities in authority and prosperity (Hofstede, 2001). Such a cultural sketch might endorse stout interpersonal and deferential links among employer and employee and signal general absolute respect for power (Hofstede, 1991; Khilji, 1995). This cultural outline suggests that employees might swallow or absorb any agitation caused by workplace mistreatment without any retaliatory or hostile action towards the organization or the boss, and continue working in the same job in the absence of too many job opportunities. This endurance of workplace mistreatment without demonstrating any overt reaction might result in a stressful mental and emotional state.

\section{LITERATURE REVIEW AND THEORETICAL FRAMEWORK}

\section{Workplace ostracism (WPO)}

Ostracism points to the extent to which an individual feels overlooked or excluded by another person, persons or group of persons (Ferris, Brown, Berry, \& Lian, 2008; Williams, 2007). It has been found to exist in several important social contexts, involving workplaces (Balliet \& Ferris, 2013; Fox \& Stallworth, 2005). Workplace peers including colleagues and/or supervisors might occasionally engage in behaviors like isolating or disconnecting others from workplacerelated social interactions, in the form of shunning, averting eye contact, exiting the room when another person comes in, transferring or shifting a person to a remote place, and failing to answer coworkers' greetings (Ferris et al., 2008; Robinson, O'Reilly, \& Wang, 2013; Xu, Huang, \& Robinson, 2017).

Ostracism is distinct from constructs of often studied workplace mistreatment behaviors such as interpersonal deviance, bullying, social undermining, aggression, and harassment in numerous aspects. First, these concepts are interactional. Ostracism is identified by a lack of interaction thereof. In other words, WPO is depicted as: "the omission of positive attention from others, rather than the commission of negative attention" (Robinson, O'Reilly, \& Wang, 2013; p 208). Because of attention omission, WPO instigates significant risk to a person's sense of belongingness, which is a basic human necessity (Baumeister \& Leary, 1995; Fiske, 2004). Such attention omission may result in some adverse mental and behavioral outcomes.

Secondly, the social background and pertinent norms verify the social acceptance of ostracism (Lustenberger \& Williams, 2009; Williams, 1997; 2007). Therefore, when a person senses ostracism; it may not be deemed the same way by another (Robinson, O'Reilly \& Wang, 2013). According to Robinson, 
O'Reilly, and Wang (2013), WPO does not necessarily entail a desire to inflict harm to the sufferer. Occasionally, individuals may overlook peers since they are preoccupied with their job tasks (Ferris et al., 2008; Williams, 2001; Zhao, Peng, \& Sheard, 2013). This suggests that a person might feel ostracized, though others have no deliberate intentions whatsoever to ostracize him/her. Sometimes people might just be busy with work. At other times, the nature of the job and context of workplace might be such that it aggravates the feeling of ostracism, though there is no intentional will of employees to involve in such acts. Due to this, the frequency of experiencing ostracism might be increased, even though it might not exist or might exist less frequently.

\section{Job stress}

The word "stress" is in part derived from old French's 'extreme,' meaning narrowness or oppression, and in part from the Latin's "stringere" meaning to draw tight. In the 17th century, such words were used to denote hardships, adversity, and strain. Today stress is frequently expressed as a sense of being overwhelmed, concerned or run-down. The term "stress" was coined by Hungarian-Canadian experimentalist Hans Selye in 1936 (Selye, 1973), who described it as the non-specific reaction of the body to any need for change. It is a reaction to any internal or peripheral stimulus that generates discrepancy in one's physiological or psychological equilibrium.

In the current literature, several definitions have been used to describe stress. This study operationalizes stress by the 'Encyclopedia of Stress,' where stress is defined as "real or an interpreted threat to the physiological or psychological integrity of an individual that results in physiological and behavioral response" (Fink, 2000).

Keeping in view that stress is a personal response to some variations in the environment, Pestonjee (1973) has tried to classify three vital areas of life, which might result in stress. These areas are job/ organization, the social sector, and the intrapsychic sector. The current study deals with the on-thejob stressor in the form of workplace ostracism since it is one of the most prevalent forms of workplace mistreatment (Fox \& Stallworth, 2005; as cited by Steinbauer, Renn, Chen, \& Rhew, 2018) and has seldom been studied in the context of the banking industry of developing nations. Ostracism might be a significant cause of stress in employees that might trigger physiological and behavioral responses in the workplace.

\section{Ostracism and stress}

According to Chung (2018), comprehensive studies have not yet inspected the connections between WPO and the perceived stress of personnel. 
The present study tries to fulfill this opening by empirically studying the association between perceived stress and workplace ostracism.

WPO has a harmful influence on the wellbeing of personnel since it is an excruciating and disliked experience (Ferris et al., 2008). Researchers have demonstrated that ostracism is related to negative affect (Williams et al., 2002), frustration, sadness, nervousness (Anderson \& Pulich, 2001; Colligan \& Higgins, 2006), emotional exhaustion (Wu et al., 2012) and adverse emotional conditions, for instance, sorrow, despair, solitude, envy, culpability, indignity, embarrassment and social apprehension (e.g., Gruter \& Masters, 1986; Leary, Koch, \& Hechenbleikner, 2001). Moreover, importantly, Williams $(1997,2001)$ proposed that ostracism can be contended as an interpersonal stressor, consequently, ensuing in stress.

\section{Ostracism and stress in light of COR theory}

Conservation of resources (COR) theory most coherently captures the essence of this idea. COR embarks on the principle that people endeavor to attain, preserve, foster and defend the belongings they centrally value (Hobfoll, 1989). COR theory posits that "stress occurs (a) when central, or key resources are threatened with loss, $(b)$ when central or key resources are lost, or $(c)$ when there is a failure to gain central or key resources following significant effort" (Hobfoll et al., 2018; p.104).

Since affiliation, belongingness, and support from coworkers and supervisors represents a critical social and job resource, when faced with silent treatment in the workplace, personnel might develop a feeling of losing a valuable resource and therefore feel stressed. Based on these arguments, it is hypothesized that:

H1: Workplace ostracism has a positive relationship with job stress.

\section{Self-efficacy (SE)}

Self-efficacy refers to a person's perception of their capability to carry out their work-related duties (Bandura, 1997; Coeurderoy, Guilmot, \& Vas, 2014; Parker, 1998). General self-efficacy (GSE) is defined as "individuals' perception of their ability to perform across a variety of different situations" (Judge, Erez, \& Bono, 1998, p. 170). According to Zhou, Ma, and Dong (2018), it advanced from social cognitive theory's (Bandura, 1997) notion of SE generality. GSE is distinct from SE, in that GSE is a comparatively steady belief about generalized competence and is like a trait, whereas $S E$ is a comparatively accommodating, task-specific belief (Chen, Gully, Whiteman, \& Kilcullen, 2000; Chen, Gully, 
\& Eden, 2001). This study will utilize these terms interchangeably. Though, wherever the term SE is used, it is operationalized as GSE.

\section{Self-efficacy, ostracism, and stress}

Personnel who display a higher level of self-efficacy can find several routes to task completion since they are apt in employing different knowledge handling actions to optimize their knowledge foundation (Bandura, 1997; Seggelen-Damen \& Dam, 2016; Yeo \& Neal, 2006). This leads to increased viability for fulfilling organizational expectations, which consecutively would lead to reduced levels of stress that they go through when completing job tasks (Schwarzer \& Hallum, 2008) mainly when the cause of stress is being targeted with ostracism.

In line with the underlying principles of COR theory, a person's SE should reduce their ostracism linked sense of stress, since this personal resource lessens the fear of not being able to accomplish their work duties (Hobfoll \& Shirom, 2000). The personal resource of SE, therefore, should reduce the probability that personnel sense more stress in stressful situations related to workplace mistreatment, specifically ostracism. According to COR theory, personnel with higher self-belief in their capabilities and expertise tend to accomplish their job-related goals more often since unconstructive feelings like stress arising due to social exclusion, will less probably diminish their resource reservoirs. Therefore, they do not need to preserve energy while at work (Hobfoll, 2001). Combining these arguments, this study predicts a moderating role of self-efficacy to offset the adverse effects of stress due to WPO.

H2: Self-efficacy moderates the relationship between workplace ostracism and stress, such that the relationship will be weaker in the presence of high self-efficacy and vice versa.

\section{Gender as moderator}

It has been observed in recent studies related to stress (e.g., Han, Shim, \& Choi, 2018) that gender and work culture can have differential effects on an employee's work-related attitudes and emotional health. According to Aquino and Thau (2009), researchers examining relationships concerning gender and mistreatment do not display a clear association among these variables. Some studies related to workplace mistreatment and gender, demonstrate them to be unrelated, (Vartia, 1996; Einarsen \& Skogstad, 1996, Zellars, Tepper, \& Duffy, 2002; Vartia \& Hyyti 2002), whereas other studies show women reporting more cases of mistreatment at work as compared to men (Aquino \& Bradfield 
2000; Cortina, Magley, Williams, \& Langhout, 2001; Tehrani, 2004; Salin, 2001). In sharp contrast, some research has also demonstrated men reporting more instances of mistreatment than women (Jennifer, Cowie, \& Ananiadou, 2003).

Such a review of the literature shows mixed results regarding the role of gender concerning mistreatment. Additionally, to enrich limited existing literature concerning gender and workplace mistreatment in Pakistan, and in line with the early socialization theory (Danziger \& Eden, 2007), this study tests the effects of gender as a moderator in the relationship between ostracism and stress, and therefore hypothesizes that:

H3: Gender has a moderating effect between workplace ostracism and perceived job stress.

\section{Work-culture as moderator}

Though gender might be an essential demographic variable, related to workplace mistreatment and the mental health of employees, Bowling and Beehr (2006) described these relationships as relatively weak as compared to the influence of work environment variables. There is a need for additional empirical research to include the broader work context for comprehending organizational behavior in public-private sector organizations (Perry, 2000). Therefore, we also include work-culture as a moderator in this study and take the public-private sector as a proxy for this variable. According to Rashid and Rashid (2012), there is an overall agreement regarding variances between public and private sector employment. They put forward that though researchers have studied differences and similarities in public and private sectors, they have found mixed results.

Public and private sector organization's work-culture differ significantly in terms of work contents, their quality, job independence, task interdependence, participation in decision-making, challenge and variety of work, task significance and quality of social relations (Baldwin \& Farley, 1991; as cited by Rashid \& Rashid, 2012; Aryee, 1992).

Studies have found mixed results regarding social relations and context in public versus private sector organizations. Jurkiewicz, Massey, and Brown, (1998) report public sector employees and supervisors to be friendly and congenial acquaintances as compared to private sector employees. On the other hand, Lyons, Duxbury, and Higgins (2006) and Khojasteh (1993) did not find evidence for this variance in their research. Gabris and Simo (1995) showed that public versus private sector employees do not vary in their need for affiliation. While, other researchers have demonstrated the public sector's work environment to be characterized by the poor quality of 
relationships, helping behavior and concern among subordinates, co-workers and bureaucratic superiors (e.g., Smith \& Nock, 1980).

Similarly, Salin's (2001) survey of 377 Finnish personnel showed that public sector employees experienced more workplace mistreatment as compared to their counterparts in the private sector. To study the effects of work-culture on the relationship between workplace ostracism and stress in Pakistani banks, we propose the following hypothesis:

H4: Work-culture has a moderating effect between workplace ostracism and perceived job stress.

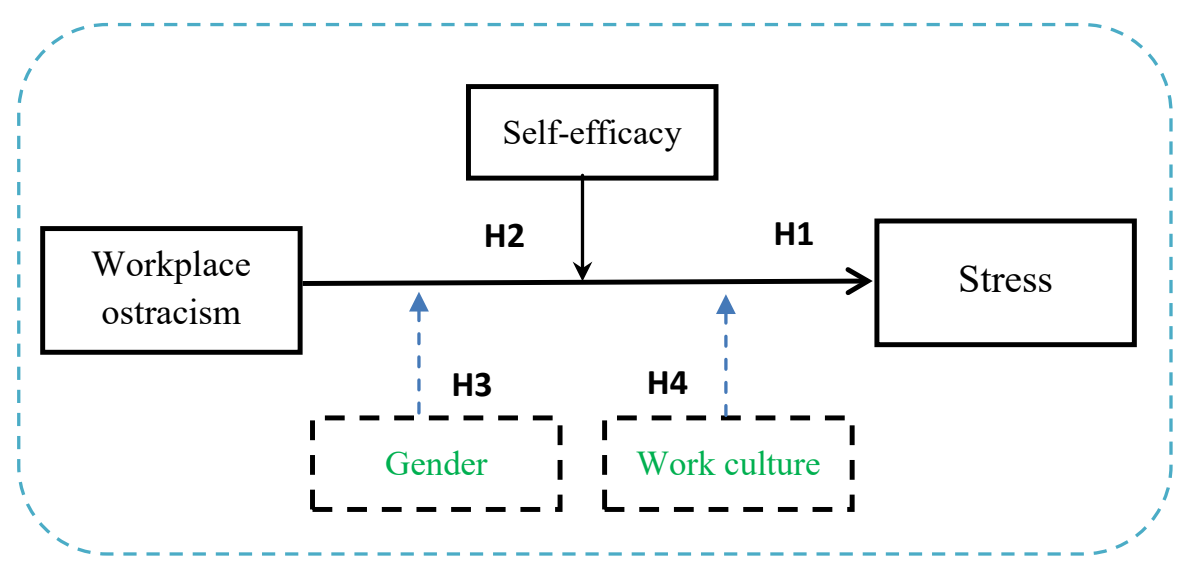

Figure 1: Theoretical framework

\section{METHODOLOGY}

The population for this research was selected from the financial, explicitly banking industry of Pakistan, to answer the call of Abubakar, Yazdian, and Behravesh (2018). The population count was unknown. Data were collected from employees working in public and private sector banks located in the Punjab region. It is imperative to ensure that the organizational environment chosen to be studied must reflect the attitudes and behaviors relevant to the study; and the variables required to be studied in the research model (Zhou \& George, 2001). Banking employees in Pakistan, from top to bottom of the hierarchy, have daily interaction with their colleagues, customers, and supervisors, and stress levels are usually high due to workload and maltreatment. The task interdependence is also high which might aggravate 
the intensity of WPO. The non-probability convenience sampling method was utilized for the study because of the geographical dispersion of banks and the fact that population size was unknown. Additionally, due to the cost and the time constraint for conducting the study, researchers were forced to go for convenience sampling. The data was collected through structured questionnaires. In Pakistan, the official language spoken in most proficient business organizations and educational institutes is English. Since banking personnel in Pakistan get their degrees from colleges and universities where the study language is also English (De Clercq, Haq, \& Azeem, 2018), it was therefore believed that participants would be able to understand and answer the questionnaire adequately and there was no need to translate the questionnaire. So, the survey was written in English. Three hundred and ninety questionnaires were floated in random banks of the South-Punjab region, of which 245 were returned. Thirty-eight were incomplete, and 8 had other errors. The respondents did not return the rest of the questionnaires at T2. A total of 219 questionnaires were received in analyzable, complete form and were included for analysis. The response rate was $63 \%$. Considering the time-lagged data collection, this response rate is acceptable (Jahanzeb \& Fatima, 2017). Comparatively more participation from male respondents (122; 56.2\%) was witnessed as compared to females $(97 ; 43.8 \%)$. Sectorwise, we received 81 responses from employees working in public sector banks, whereas 138 were from private sector banks.

\section{Instruments}

\section{WPO}

A ten-item scale created and validated by Ferris et al. (2008) was utilized to measure workplace ostracism. The scale is a five-point Likert scale. The responses ranged from 1 ('strongly disagree') to 5 ('strongly agree'). Some of the items from the questionnaire were 'Others ignored me at work', 'Others left the area when I entered', 'Others at work do not invite me or ask me when they go out for a break', 'Others do not talk to me at work' and 'My greetings have gone unanswered at work'. This scale has been used by earlier researchers, for instance by Chung (2018), where the reliability of this scale was 0.97 and by Khair and Fatima (2017) with a Cronbach's alpha of 0.89.

\section{Self-efficacy}

An eight-item scale developed and validated by Chen, Gully, and Eden (2001) was used to measure self-efficacy. This was also a five-point Likert scale, and 
responses ranged from 1 ("strongly disagree") to 5 ("strongly agree"). Some of the items from the scale are: "I will be able to achieve most of the goals that I have set for myself" and "I am confident that I can perform effectively on many different tasks." The Cronbach's alpha for this scale was 0.81 as used by Zhou, Ma, and Dong (2018).

\section{Stress}

A seven-item scale (Galinsky, Bond, \& Swanberg, 1998) was used to measure stress and inquired about how frequently over the last three months the respondents felt in a variety of ways (e.g., "nervous or stressed," "emotionally drained from work"). The response options were in the form of a five-point Likert scale. This scale is like the one used by Kandel, Davies, and Raveis (1985) regarding content. Earlier, Behson (2005) utilized the same scale.

\section{Control variables}

Age, education, and experience were included as control variables since earlier studies have shown these to affect ostracism and burnout related outcomes and have been controlled in recent studies (e.g., Chung, 2018; Lee \& Ok, 2014). This will ensure that the relationships between variables are not confounded.

\section{DATA ANALYSIS}

The data was analyzed using the Process Macros (Hayes, 2017) as it is one of the latest and practical techniques to deal with latent variables. The study aimed to unpack the direct and interactive effect of workplace ostracism on stress using self-efficacy as a moderating variable. The Process Macros model-1 has been applied to get the desired results. Before testing the primary hypotheses, various tests were carried out in SPSS and AMOS to check the viability of the data to measure the relationship above. These tests involved confirmatory factor analysis, descriptive statistics, validity \& reliability analysis, correlation analysis and, finally, hierarchical regression analysis.

\section{Descriptive and correlation analysis}

To test the underlying supposition, researchers obtained data from the Banking industry operating in the southern Punjab region of Pakistan. The descriptive statistics of the respondents are presented in Table 1 which indicates that on average, the age of the respondents was above 31 years with a variation of 7-8 years of age. Further, on average their experience is 
above seven years with a variation of six years, which means respondents were a mix of young and experienced employees. Moreover, their education level was above graduation, and comparatively more participation from male respondents was witnessed, i.e., male 122 (56.2\%) and female 97 (43.8\%). Sector-wise, we received 81 responses from employees working in public sector banks, whereas 138 were from private sector banks. The correlation values indicate a moderate correlation among all constructs (see Table 1). This is by the guidelines of Cohen, Cohen, West, and Aiken (2013).

Regarding the instruments, the only items that were included had above 0.4-factor loading as per criteria set by DeCoster (1998) and had above 1 eigenvalue. The values of Cronbach (1951) surpassed the qualifying criteria as laid down by George and Mallery (2016), i.e., "Reliability range: $\geq 0.9$ =excellent, $\geq 0.8=$ good,$\geq 0.7=$ acceptable,$\geq 0.6=$ questionable $\geq=0.5=$ poor and $<0.5$ =unacceptable". The values of alpha were found to be above the required criteria value, i.e., $\mathrm{WO}=0.88, \mathrm{SE}=0.87$ and $\mathrm{ST}=0.78$.

Table 1. Descriptive and correlation analysis

\begin{tabular}{lrlllllll}
\hline Constructs & Mean & SD & AG & EP & EL & WPO & SE & ST \\
\hline Age (AG) & 31.04 & 7.75 & 1 & & & & & \\
Experience (EP) & 7.46 & 6.26 & $0.98^{* *}$ & 1 & & & & \\
Education Level (EL) & 2.20 & 0.54 & $0.29^{* *}$ & $0.42^{* *}$ & 1 & & & \\
Workplace Ostracism (WPO) & 3.38 & 0.85 & -0.12 & -0.08 & -0.11 & 1 & & \\
Self-Efficacy (SE) & 3.31 & 0.89 & 0.08 & -0.02 & -0.02 & $-0.54^{* *}$ & 1 & \\
Stress (ST) & 3.23 & 0.64 & $0.17^{*}$ & 0.12 & 0.12 & $0.61^{* *}$ & $-0.65^{* *}$ & 1 \\
\hline Note: ${ }^{*} \rho<0.05,{ }^{* *} \rho<0.01$. & & & & & & & &
\end{tabular}

\section{Confirmatory Factor Analysis (CFA)}

AMOS-Version 20 was used to carry out the Confirmatory Factor Analysis (CFA). It was executed to ensure the validity of the instrument and its appropriateness in the given context as it is important to generalize the obtained results of the study (Hoyle, 1991). The CFA was completed using the guidelines of McArdle (1996) as it is suitable to reach the model fit indices step by step based on the standards present in work done by Kline (2006). The present study involved three latent variables; workplace ostracism having a ten items scale; self-efficacy having an eight items scale; and stress with a seven items scale. The fit indices have been attained by following Byrne (2013). The results suggested that all constructs have been satisfactorily operationalized and measure what they intend to measure (see table 2). The model fit indices showed suitable figures within acceptable ranges i.e., 
Chi-square $/ \mathrm{df}=2.42<3.00, \mathrm{RMSEA}=0.057<0.08$ and $\mathrm{GFI}=0.911-\mathrm{BBNNFI}=$ $0.969-\mathrm{CFI}=0.943-\mathrm{IFI}=0.958>0.90$ (see Table 2).

Further, Table 2 also explains the Average Variance Explained (AVE). It is an indicator that assesses the convergent validity. All the values surpassed the value of 0.5 , which is an acceptable criterion jointly with the reliability coefficient alpha having higher than 0.7 values. This ensured the constructs have convergent validity. The values of the indicators laid within an acceptable range i.e., workplace ostracism ( $\alpha=0.88, A V E=0.61)$, self-efficacy $(\alpha=0.87$, $A V E=0.62)$ and stress $(\alpha=0.78, A V E=0.57)$. Further, to investigate the discriminant validity, Average Shared Variance (ASV) was calculated. However, before computing ASV, it was observed that the correlation among constructs was less than 0.7 (see Table 1). All latent constructs have correlation coefficient values of less than 0.7. Here the highest correlation exists between SE \& ST (i.e., 0.65$)$, the square of which is $0.42(42 \%)$ which is manageable as it is below 0.50 . These values ensure the distinctiveness of the factors.

Furthermore, the values of ASV are also manageable and ensured the unique capability of the construct, i.e., workplace ostracism $=0.22$, selfefficacy $=0.21$ and stress $=0.18$. The values of Composite Reliability (CR) are also within the acceptable range as $0.89,0.87 \& 0.79$ are more significant than 0.70 for workplace ostracism, self-efficacy and stress, respectively, as defined by Hair, Black, Babin, and Anderson (2010). Hence, from the values of $\mathrm{CR}, \mathrm{AVE}, \mathrm{ASV}$, and MSV, it can be determined that factors are valid and reliable enough to measure what they are intended to measure.

Table 2. Confirmatory Factor Analysis and scale reliability

\begin{tabular}{lllllllllll}
\hline $\begin{array}{l}\text { Construct } \\
\text { Descriptions }\end{array}$ & $\begin{array}{l}\text { Chi- } \\
\text { Square/ } \\
\text { df }\end{array}$ & RMSEA & GFI & CFI & BBNNFI & IFI & CR & AVE & MSV & ASV \\
\hline Fit Indices & 2.42 & 0.057 & 0.911 & 0.943 & 0.969 & 0.958 & & & & \\
WPO & & & & & & & 0.89 & 0.61 & 0.42 & 0.22 \\
SE & & & & & & & 0.87 & 0.62 & 0.41 & 0.21 \\
ST & & & & & & & 0.79 & 0.57 & 0.39 & 0.18 \\
\hline
\end{tabular}

Note: acceptable range of indices Chi-square/df <3.0, GFI-CFI-BBNNFIIFI $>0.90$, RMSEA $<0.08$, CR= Composite Reliability, AVE= Average Variance Extracted, WPO= Workplace Ostracism, SE $=$ Self-Efficacy, $\mathrm{ST}=$ Stress, MSV= Maximum Shared Variance, ASV= Average Shared Variance.

\section{Hypotheses testing}

After conducting the initial analysis, which ensured the validity and reliability of the data, the descriptive and correlation analysis, the next step is the testing of the leading hypotheses for which this study was conducted. The results of the critical hypotheses were obtained by utilizing the latest 
method introduced by Hayes (2017), more renowned as Process Macro (Model-1 was used) using SPSS.

\section{Checking pre-requisites for regression analysis}

Before executing the hierarchical linear regression, preliminary tests were conducted to ensure the appropriateness of the data for regression analysis. Since data was found to be reliable and valid in the earlier section, the skewness and kurtosis tests were carried out next to certify the normality of the data. The data was acceptable within standards set by Hair et al., (2010) as the values of skewness and kurtosis were found to be between -1 and +1 . Further plotting of these values in a graph resulted in a straight line that confirmed its normality.

Moreover, the standardized residuals centrality to zero with linear relationship guaranteed that there was no element of heteroscedasticity in the data. The results were also in tolerance since the Variance Inflation Factor (VIF) was also within the acceptable ranges, i.e., tolerance 0.41 and VIF 2.15 (Kline, 2014). With the analysis of heteroscedasticity, tolerance, and variance inflation factor, it was confirmed that there was no multi-collinearity in the data. Additionally, to confirm the non-existence of auto-correlation, a Durbin-Watson test was executed, and the results showed that there was no autocorrelation prevailing in the data. The results of the pre-requisite analysis above allowed researchers to execute the regression analysis with full confidence.

\section{Direct effect}

To check the effect of workplace ostracism on stress and the interactive effect of self-efficacy on workplace ostracism and stress, at the first level, a hierarchical linear regression analysis was conducted using SPSS. The results of the direct effect revealed that workplace ostracism is positively related to stress as there was a $37 \%$ variation found in stress due to workplace ostracism ( $R 2=0.37, t=9.32, \rho<0.05)$. The results of the F-statistics confirmed the general viability of the overall regressed model $(F=108.543, \rho<0.05)$. It can, therefore, be concluded that employees ostracized in the workplace remain under stress (Table 3 ).

Table 3. Results of regression analysis

\begin{tabular}{lcccccc}
\hline Relationship & $\mathbf{R}^{\mathbf{2}}$ & $\boldsymbol{\Delta} \mathbf{R}^{\mathbf{2}}$ & $\mathbf{f}$-value & $\boldsymbol{\beta}$ & t-value & $\boldsymbol{\rho}$ \\
\hline WPO $\rightarrow$ ST & 0.37 & & 108.543 & 0.56 & 9.32 & $* *$ \\
\hline WPO*SE (ST) & & 0.063 & & $0.423,0.627,0.841$ & & $* *$ \\
\hline
\end{tabular}

Note: ${ }^{* *} \mathrm{p}<0.05, \mathrm{WPO}=$ Workplace Ostracism, $\mathrm{ST}=$ Stress. 


\section{Moderating effect of SE}

In the second phase, the interactive effect of self-efficacy on the relationship between workplace ostracism and stress was analyzed. The results reflected that self-efficacy buffers the adverse effect of workplace ostracism on stress $\left(\Delta R^{2}=0.063, \rho<0.05\right)$. The employees having a high level of self-efficacy can prevent the negative consequences of workplace ostracism and sense comparatively lesser levels of stress. At the second level, the hierarchical linear regression results were reconfirmed through Process Macros and are shown in Table 4. The results indicated that self-efficacy could be a tool used by employees to safeguard themselves from the harmful effects of workplace ostracism.

Table 4: Moderating Effect Through Bootstrapping Process

\begin{tabular}{|c|c|c|c|c|c|c|c|c|c|c|c|}
\hline Outcome & Predictor & $R^{2}$ & $\Delta R^{2}$ & Effects & f-value & $\beta$ & SE & t-value & LLCI & ULCI & $\rho$ \\
\hline \multirow[t]{4}{*}{ ST } & & 0.370 & & & 108.543 & & & & & & ** \\
\hline & WPO & & & & & 0.420 & 0.134 & 9.320 & 1.465 & 2.990 & $* *$ \\
\hline & SE & & & & & 0.620 & 0.130 & 7.760 & 1.876 & 3.143 & ** \\
\hline & WPO*SE & & 0.063 & & 167.480 & 0.840 & 0.035 & 10.440 & 2.122 & 3.552 & ** \\
\hline
\end{tabular}

Note: ${ }^{* *} \rho<0.05$, IV=Workplace Ostracism (WPO), DV=Stress (ST), M=Self-Efficacy (SE), LLCl=Lower Level Confidence Interval, ULCl= Upper-Level Confidence Interval, Applied Model 1 of Hayes (2017) with 5000 bootstrapping process. $\mathrm{M}$ values at $18 \mathrm{th}, 54 \mathrm{th}$, and 85 th percentiles.

The graphical representation of the mentioned interaction effect is shown in Figure 1, which also explains that a high level of self-efficacy helps employees to reduce their stress level induced by workplace ostracism.

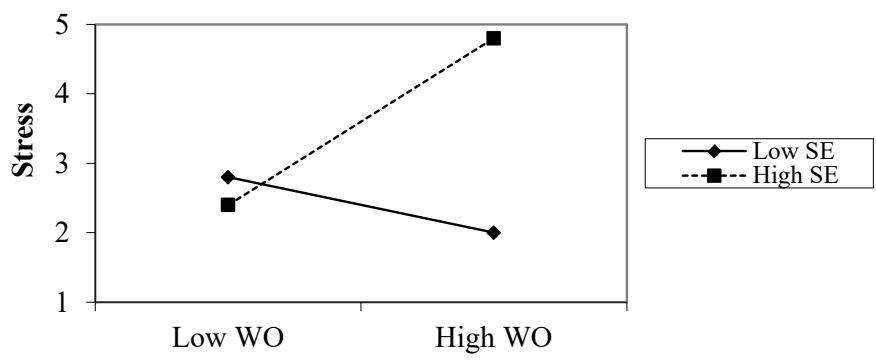

Figure 2. Interaction effect of self-efficacy on the relationship between workplace ostracism and stress 


\section{Moderating effects of gender and culture}

Since differences were expected between the groups of gender and workculture, regarding WPO and stress, these were included as two possible moderators in the relationship between workplace ostracism and stress, which gives a shape of multi-group perspective to this study. The dimensions of these moderators are mutually exclusive (i.e., for gender: male and female; and for work-culture: public and private sector). The free and structural weight constraint models were compared to inspect the difference between the two groups by observing the change in the chi-square value.

The statistics reflected in Table 5 are showing a difference of 244.283 for gender and 173.581 for work-culture in chi-square values against the critical value of 0.05 extracted from the table at a significance level of 0.05 . The results confirmed that there is a significant difference between the two groups in both cases, i.e., gender and work-culture.

Table 5. Comparison of free and constraint models for verification of the moderating effect of gender and culture

\begin{tabular}{|c|c|c|c|c|c|c|c|}
\hline Moderator & Model & $\mathrm{X}^{2}$ & df & CFI & RMSEA & $\Delta \mathrm{X}^{2} / \Delta \mathrm{df}$ & Sig. \\
\hline \multirow[t]{2}{*}{ Gender } & Free Model & 2945.271 & 335 & 0.891 & 0.075 & -- & - \\
\hline & Structural weight constrained model & 3189.554 & 300 & 0.874 & 0.071 & 6.98 & Yes \\
\hline \multirow[t]{2}{*}{ Culture } & Free Model & 2788.191 & 335 & 0.905 & 0.066 & -- & -- \\
\hline & Structural weight constrained model & 2961.772 & 300 & 0.893 & 0.062 & 4.96 & Yes \\
\hline
\end{tabular}

After observing a remarkable difference between the two groups, the path coefficients and critical values were calculated to test the strength of the moderating effects of these two groups on the stated relationship between workplace ostracism and stress. The values in table 6 show that females are more prone to stress due to ostracism as compared to male employees. Furthermore, the stress caused due to workplace ostracism is more prevalent in the public sector banks of Pakistan as compared to the banks operating in the private sector.

Table 6. Comparison of path coefficients

\begin{tabular}{lllllll}
\hline Path & Male & Female & CR & Public & Private & CR \\
\hline WOS $\rightarrow$ Stress & $0.512^{*}$ & $0.715^{*}$ & 3.544 & $0.672^{*}$ & $0.213^{*}$ & 2.187 \\
\hline
\end{tabular}

Note: ${ }^{*} p<0.01$. 


\section{DISCUSSION}

The prevalence of mistreatment represents a significant problem in contemporary workplaces, which results in severe consequences for the organization as well as mistreated employees; from physical and mental harm to deviant behaviors and turnover. This study extends the present body of knowledge by showing that WPO, as a passive form of mistreatment, affects employees' mental state and is related to stress. Earlier studies have shown stress to be linked with detrimental outcomes (Chung, 2018) but WPO has seldom been linked to stress and needed to be studied from a stress point of view (Wu et al., 2012; Chung, 2018), which makes this study a significant contribution to the present literature. COR theory ideally suited the cause, being a stress theory that describes the motivation that drives humans to both maintain their current resources and to pursue new resources. It offered an insightful perspective to comprehend the impact of WPO since WPO depletes valuable resources which are vital to assist personnel in the workplace (Leung et al., 2011). In such a situation, a person's defense mechanism is triggered. In an attempt to protect against additional resource loss, personnel face continuous stress and go through more resource deficit, resulting in a range of adverse work-related outcomes.

The study findings show that the social environment in the workplace is significant and can critically disturb the mental and emotional well-being of organizational members. As earlier researchers found workplace ostracism to be positively associated with anxiety and depression (Ferris et al., 2008), emotional exhaustion (Wu et al., 2012) and negative affect (Williams et al., 2002), this study found workplace ostracism to be positively related to perceived stress. Exclusion and silent treatment can produce negative self-perceptions, and such an emotional state can act supplementarily in authorizing a person to sense a lack of control and a resource loss (e.g., need of belongingness). When people are ostracized, they feel a lack of social support from colleagues and supervisors, and thus, a resource loss is perceived since social support has been claimed to be a critical resource in stressful situations (Hobfoll, 1989). Because of these undesirable experiences, ostracized people will likely perceive stress; consequently, suggesting that WPO can be another source of stress in the workplace.

Furthermore, earlier studies have demonstrated that people belonging to collectivistic societies are inclined to give undue importance to harmonious interpersonal relations (Yang, 1993), and therefore, such individuals might be more susceptible to workplace mistreatment in the form of ostracism (Powell, Francesco \& Ling, 2009). Being relatively high in power distance, collectivism and uncertainty avoidance points to a society with high rule orientation and 
support to high disparities in authority and prosperity (Hofstede, 2001). Such a cultural sketch might endorse stout interpersonal and deferential links among employer and employee and signal general absolute respect for power (Hofstede, 1991; Khilji, 1995). This cultural outline suggests that employees might swallow or absorb any agitation caused by workplace mistreatment without any retaliatory or hostile action towards the organization or the boss and continue working in the same job. Such an endurance of workplace mistreatment, without demonstrating any overt reaction, might result in a more stressful mental and emotional state leading to adverse work-related as well as non-work related outcomes.

Another significant contribution of this study is the demonstration that SE acts as a boundary condition in mitigating the adverse effects of WPO. Such variables are underexplored factors that inform this process. Consistent with COR theory, to the extent that employees are exposed to co-worker's disrespectful work behaviors, the personal resource of selfefficacy is particularly useful for mitigating the anxiety they experience due to mistreatment. The more confident employees are about their capabilities, the less likely they are to feel overburdened by emotional, mental state due to their ability to complete their job tasks successfully (Bandura, 1997) which frees up some of their energy to devote to positive performance-enhancing activities (Hobfoll \& Shirom, 2000; McCarthy, Trougakos, \& Chang, 2016). Thus, lower stress, due to higher confidence in their capabilities, is instrumental and enables employees to focus on the successful execution of their work tasks instead of being distracted by workplace anti-social context. The collaborative effect of SE and WPO on stress thus aligns with the COR logic that efficacious employees utilize personal resource of efficacy to meet their job requirements and find it particularly useful in the presence of unfavorable resource-draining work conditions. Overall, the moderated model of the study showed that the effects of SE mitigate the effects of WPO, adding to the extant literature on boundary conditions for workplace ostracism and its consequences.

Lastly, as mentioned before, earlier studies have demonstrated mixed results regarding the influence of gender (Vartia \& Hyyti, 2002; Tehrani, 2004; Jennifer, Cowie, \& Ananiadou, 2003) and work-culture (Jurkiewicz, Massey and Brown, 1998; Khojasteh, 1993; Salin, 2001), in relation to workplace mistreatment. This study has shown that, in Pakistani banks, gender, as well as work-culture, plays an important role. Women here are more prone to stress due to workplace ostracism, whereas the phenomenon of ostracism is more prevalent in public sector banks as compared to private sector banks. These findings are in line with the findings of Smith \& Nock (1980) and Salin (2001). 


\section{CONCLUSION}

This research study has tried to extend the current body of knowledge by investigating the relationship between workplace ostracism and stress based on the COR theory. Our model has shown that although workplace ostracism leads to stress in employees, self-efficacy as a moderator and personal resource can mitigate the strength of this relationship. The belief in self-capabilities and the confidence to carry out any activity successfully can weaken the strength of any harmful stress they feel due to WPO. Data was collected from the banking industry in the southern Punjab region of Pakistan from employees working in public and private sector banks. Results have confirmed all the hypotheses and found the moderating impacts of selfefficacy on the relationship between workplace ostracism and stress. This implies that when workplace ostracism is increased, harmful stress might be reduced to a certain degree due to the presence of SE. Additionally, the study also provided support for the fact that women feel more stressed due to WPO and WPO prevails more in banks operating in the public sector of Pakistan as compared to private sector banks.

\section{Theoretical contribution}

The conservation of resources theory endorsed the association between workplace ostracism, stress, and self-efficacy in the context of the banking industry in the Punjab region of Pakistan. COR theory posits that "stress occurs $(a)$ when central, or key resources are threatened with loss, $(b)$ when central or key resources are lost, or $(c)$ when there is a failure to gain central or key resources following significant effort" (Hobfoll et al., 2018; p.104). This research explains and provides evidence that workplace mistreatment in the form of ostracism is considered as a threat to a valuable resource (need for belongingness) and is therefore related to stress. If not controlled for, such stress might lead to decreased job satisfaction, job performance, deviant/counterproductive behaviors, and increased turnover.

The research also utilized self-efficacy as a personal resource in the premises of COR for mitigating the adverse effect of resource loss arising from WPO and contributing to stress. Self-efficacy is the degree of belief in one's capabilities to be successful in a variety of situations. This study has demonstrated that individuals who have a higher sense of self-efficacy would be less affected by the negative influence of WPO. Though some level of stress is considered necessary for efficient and effective working, yet to the degree where stress acts as harmful, self-efficacy might be used as a useful resource for mitigating its adverse effects. Highly self-efficacious individuals are less 
prone to sense stress in the face of mistreatment. They focus and dwell more on their capabilities rather than on other's behavior that results in stress. Self-efficacy is one of the dimensions of psychological capital, others being hope, optimism, and resilience. It would be interesting to study the effect of these dimensions, generally or exclusively, on the relation between WPO or other forms of workplace mistreatment and stress.

\section{References}

Abubakar, A. M., Yazdian, T. F., \& Behravesh, E. (2018). A riposte to ostracismand tolerance to workplace incivility: A generational perspective. Personnel Review, 47(2), 441-457. https://doi.org/10.1108/PR-07-2016-0153

American Psychiatric Association. (2000). Diagnostic and Statistical Manual of Mental Disorders (4a. text revision.). Washington, DC, EE. UU.: First, $\mathrm{MB}, \mathrm{Ed}$.

Anderson, P., \& Pulich, M. (2001). Managing workplace stress in a dynamic environment. The Health Care Manager, 19(3), 1-10. https://doi. org/10.1097/00126450-200119030-00002

Aquino, K., \& Bradfield, M. (2000). Perceived victimization in the workplace: The role of situational factors and victim characteristics. Organization Science, 11(5), 525-537. https://doi.org/10.1287/orsc.11.5.525.15205

Aquino, K., \& Thau, S. (2009). Workplace victimization: Aggression from the target's perspective. Annual Review of Psychology, 60, 717-741. https:// doi.org/10.1146/annurev.psych.60.110707.163703

Aryee, S. (1992). Public and private sector professionals: A comparative study of their perceived work experience. Group \& Organization Management, 17(1), 72-85. https://doi. org/10.1177\%2F1059601192171006

Badar, M. R. (2011). Factors causing stress and impact on job performance, "A case study of banks of Bahawalpur, Pakistan." European Journal of Business and Management, 3(12), 9-17. https://iiste.org/Journals/index. php/EJBM/article/view/717

Balliet, D., \& Ferris, D. L. (2013). Ostracism and prosocial behavior: A social dilemma perspective. Organizational Behavior and Human Decision Processes, 120(2), 298-308. https://doi.org/10.1016/j. obhdp.2012.04.004

Bandura, A. (1997). Self-efficacy: The Exercise of Control. New York, NY: Freeman.

Baumeister, R. F., \& Leary, M. R. (1995). The need to belong: Desire for interpersonal attachments as a fundamental human motivation. Psychological Bulletin, 117(3), 497-529. https://doi.org/10.1037/00332909.117.3.497 
Behson, S. J. (2005). The relative contribution of formal and informal organizational work-family support.Journal of Vocational Behavior, 66(3), 487-500. https://doi.org/10.1016/j.jvb.2004.02.004

Bowling, N. A., \& Beehr, T. A. (2006). Workplace harassment from the victim's perspective: A theoretical model and meta-analysis. Journal of Applied Psychology, 91(5), 998. https://psycnet.apa.org/doi/10.1037/00219010.91.5.998

Byrne, B. M. (2013). Structural Equation Modeling with AMOS: Basic Concepts, Applications, and Programming. New York: Routledge.

Chaudhry, N. I., Mahesar, H. A., Pathan, S. K., Arshad, A., \& Butt, A. (2017). The mediating role of workplace interpersonal mistreatment: An empirical investigation of banking sector of Pakistan. Journal of Business Studies, 13(1), 73-88. http://ojs.ilmauniversity.edu.pk/index.php/jbs/article/ view/18/17

Chen, G., Gully, S. M., \& Eden, D. (2001). Validation of a new general selfefficacy scale. Organizational Research Methods, 4(1), 62-83. https:// doi.org/10.1177\%2F109442810141004

Chen, G., Gully, S. M., Whiteman, J. A., \& Kilcullen, R. N. (2000). Examination of relationships among trait-like individual differences, state-like individual differences, and learning performance. Journal of Applied Psychology, 85(6), 835-847. https://psycnet.apa.org/doi/10.1037/00219010.85 .6 .835

Chung, Y. W. (2018). Workplace ostracism and workplace behaviors: A moderated mediation model of perceived stress and psychological empowerment. Anxiety, Stress, \& Coping, 31(3), 304-317. https://doi.or $\mathrm{g} / 10.1080 / 10615806.2018 .1424835$

Coeurderoy, R., Guilmot, N. \& Vas, A. (2014). Explaining factors affecting technological change adoption: A survival analysis of an information system implementation. Management Decision, 52(6), 1082-1100. https://doi.org/10.1108/MD-10-2013-0540

Cohen, J., Cohen, P., West, S. G., \& Aiken, L. S. (2013). Applied Multiple Regression/Correlation Analysis for the Behavioral Sciences. New York: Routledge.

Colligan, T. W., \& Higgins, E. M. (2006). Workplace stress: Etiology and consequences. Journal of Workplace Behavioral Health, 21(2), 89-97. https://doi.org/10.1300/J490v21n02_07

Cortina, L. M., Magley, V. J., Williams, J. H., \& Langhout, R. D. (2001). Incivility in the workplace: Incidence and impact. Journal of Occupational Health Psychology, 6(1), 64. https://psycnet.apa.org/doi/10.1037/10768998.6.1.64

Cronbach, L. J. (1951). Coefficient alpha and the internal structure of tests. Psychometrika, 16(3), 297-334. https://doi.org/10.1007/BF02310555

Danziger, N., \& Eden, Y. (2007). Gender-related differences in the occupational aspirations and career-style preferences of accounting students: A cross-sectional comparison between academic school 
years. Career Development International, 12(2), 129-149. https://doi. org $/ 10.1108 / 13620430710733622$

De Clercq, D., Haq, I. U., \& Azeem, M. U. (2018). Self-efficacy to spur job performance: Roles of job-related anxiety and perceived workplace incivility. Management Decision, 56(4), 891-907. https://doi. org/10.1108/MD-03-2017-0187

DeCoster, J. (1998). Overview of factor analysis. Retrieved 10th October, 2018, from http://www.stat-help.com/notes.html

Di Marco, D., Martinez-Corts, I., Arenas, A., \& Gamero, N. (2018). Spanish validation of the shorter version of the workplace incivility scale: An employment status invariant measure. Frontiers in Psychology, 9, 959. https://doi.org/10.3389/fpsyg.2018.00959

Duffy, M. K., Ganster, D. C., \& Pagon, M. (2002). Social undermining in the workplace. Academy of Management Journal, 45(2), 331-351. https:// doi.org/10.5465/3069350

Einarsen, S. (2000). Harassment and bullying at work: A review of the Scandinavian approach. Aggression and Violent Behavior, 5(4), 379-401. https://doi.org/10.1016/S1359-1789(98)00043-3

Einarsen, S., \& Skogstad, A. (1996). Bullying at work: Epidemiological findings in public and private organizations. European Journal of Work and Organizational Psychology, 5(2), 185-201. https://doi. org/10.1080/13594329608414854

Ferris, D. L., Brown, D. J., Berry, J. W. \& Lian, H. (2008). The development and validation of the workplace ostracism scale. Journal of Applied Psychology, 93, 1348-66. https://psycnet.apa.org/doi/10.1037/a0012743

Fink, G. (2000). Encyclopedia of Stress. London, UK: Academic Press.

Fiske, S. T. (2004). Intent and ordinary bias: Unintended thought and social motivation create casual prejudice. Social Justice Research, 17(2), 117127. https://doi.org/10.1023/B:SORE.0000027405.94966.23

Fox, S., \& Stallworth, L. E. (2005). Racial/ethnic bullying: Exploring links between bullying and racism in the US workplace. Journal of Vocational Behavior, 66(3), 438-456. https://doi.org/10.1016/j.jvb.2004.01.002

Gabris, G. T., \& Simo, G. (1995). Public sector motivation as an independent variable affecting career decisions. Public Personnel Management, 24(1), 33-51. https://doi.org/10.1177\%2F009102609502400103

Galinsky, E., Bond, J. T., \& Swanberg, J. E. (1998). 1997 National Study of the Changing Workforce. New York: Families and Work Institute.

George, D., \& Mallery, P. (2016). IBM SPSS Statistics 23 Step by Step: A Simple Guide and Reference. New York: Routledge.

Gilligan, C. (1982). In a Different Voice. Psychological Theory and Women's Development. Cambridge, MA: Harvard University Press

Gruter, M., \& Masters, R. D. (1986). Ostracism as a social and biological phenomenon: An introduction. Ethology and Sociobiology, 7, 149-158. https://doi.org/10.1016/0162-3095(86)90043-9 
Hair, J. F. Black. W.C., Babin., B.J. \& Anderson R.E. (2010) Multivariate Data Analysis, a Global Perspective. New Jersey. Pearson.

Han, S. L., Shim, H. S., \& Choi, W. J. (2018). The effect of emotional labor of college administrative service workers on job attitudes-mediating effect of emotional labor on trust and organizational commitment. Frontiers in Psychology, 9, 2473. https://doi.org/10.3389/fpsyg.2018.02473

Harnois, C. E., \& Bastos, J. L. (2018). Discrimination, harassment, and gendered health inequalities: Do perceptions of workplace mistreatment contribute to the gender gap in self-reported health? Journal of Health and Social Behavior, 59(2), 283-299. https:// doi.org/10.1177\%2F0022146518767407

Hayes, A. F. (2017). Introduction to Mediation, Moderation, and Conditional Process Analysis: A Regression-Based Approach. London, New York: The Guilford Press.

Hobfoll, S. E. (1989). Conservation of resources: A new attempt at conceptualizing stress. American Psychologist, 44, 513-524. https://doi. org/10.1037/0003-066X.44.3.513

Hobfoll, S. E. (2001). The influence of culture, community, and the nested-self in the stress process: Advancing conservation of resources theory. Applied Psychology, 50(3), 337-421. https://doi.org/10.1111/1464-0597.00062

Hobfoll, S. E., Halbesleben, J., Neveu, J. P., \& Westman, M. (2018). Conservation of resources in the organizational context: The reality of resources and their consequences. Annual Review of Organizational Psychology and Organizational Behavior, 5, 103-128. https://doi.org/10.1146/annurevorgpsych-032117-104640

Hobfoll, S.E. \& Shirom, A. (2000). Conservation of resources theory: Applications to stress and management in the workplace. In R.T. Golembiewski (Ed.), Handbook of Organization Behavior (pp. 57-81). New York, NY: Dekker.

Hofstede, G. (1991). Cultures and Organizations. Intercultural Cooperation and its Importance for Survival. Software of the Mind. London: McGraw-Hill

Hofstede, G. (2001). Culture's Consequences: Comparing Values, Behaviors, Institutions and Organizations Across Nations. London: Sage Publications.

Hoyle, R. H. (1991). Evaluating measurement models in clinical research: Covariance structure analysis of latent variable models of self-conception. Journal of Consulting and Clinical Psychology, 59(1), 67. https://doi. org/10.1037\%2F0022-006X.59.1.67

Jahanzeb, S., \& Fatima, T. (2017). How workplace ostracism influences interpersonal deviance: The mediating role of defensive silence and emotional exhaustion. Journal of Business and Psychology, 33, 1-13. https://doi.org/10.1007/s10869-017-9525-6

Jennifer, D., Cowie, H., \& Ananiadou, K. (2003). Perceptions and experience of workplace bullying in five different working populations. Aggressive Behavior: Official Journal of the International Society for Research on Aggression, 29(6), 489-496. https://doi.org/10.1002/ab.10055 
Judge, T. A., Erez, A., \& Bono, J. E. (1998). The power of being positive: The relation between positive self-concept and job performance. Human Performance, 11(2-3), 167-187. https://doi.org/10.1080/08959285.199 8.9668030

Jurkiewicz, C. L., Massey Jr, T. K., \& Brown, R. G. (1998). Motivation in public and private organizations: A comparative study. Public Productivity \& Management Review, 230-250. https://doi.org/10.2307/3380856

Kandel, D. B., Davies, M., \& Raveis, V. H. (1985). The stressfulness of daily social roles for women: Marital, occupational and household roles. Journal of Health and Social Behavior, 26, 64-78. https://doi.org/10.2307/2136727

Khair, Q., \& Fatima, T. (2017). Interactive effects of workplace ostracism and belief in reciprocity on fear of negative evaluation. Pakistan Journal of Commerce \& Social Sciences, 11(3). http://hdl.handle.net/10419/188322

Khan, M. A., Safwan, N., \& Ahmad, A. (2011). Modeling link between internal service quality in human resources management and employee's retention: A case of Pakistani privatized and public sector banks. African Journal of Business Management, 5(3), 949-959. https://doi.org/10.5897/ AJBM10.829

Khan, M. J., Aslam, N., \& Riaz, M. N. (2012). Leadership Styles as Predictors of Innovative Work Behavior. Pakistan Journal of Social \& Clinical Psychology, 9(2). https://www.gcu.edu.pk/FullTextJour/PJSCS/2012/3.pdf

Khattak, J. K., Khan, M. A., Haq, A. U., Arif, M., \& Minhas, A. A. (2011). Occupational stress and burnout in Pakistan's banking sector. African Journal of Business Management, 5(3), 810-817. https://doi.org/10.5897/ AJBM10.395

Khilji, S.E. (1995). International human resource management in Pakistan. Unpublished MPhil thesis. Cambridge: University of Cambridge.

Khojasteh, M. (1993). Motivating the private vs. public sector managers. Personnel Administration, 22(3), 391-401. https://doi.org/10. 1177\%2F009102609302200304

Kline, P. (2014). An Easy Guide to Factor Analysis.New York: Routledge.

Kline, R. B. (2006). Structural Equation Modeling. London, New York: The Guilford Press.

Leary, M. R., Koch, E. J., \& Hechenbleikner, N. R. (2001). Emotional responses to interpersonal rejection. In M. R. Leary (Ed.), Interpersonal Rejection (pp. 145-166). New York, NY: Oxford University Press.

Lee, J. J., \& Ok, C. M. (2014). Understanding hotel employees' service sabotage: Emotional labor perspective based on conservation of resources theory. International Journal of Hospitality Management, 36, 176-187. https://doi.org/10.1016/j.ijhm.2013.08.014

Leung, A. S., Wu, L. Z., Chen, Y. Y., \& Young, M. N. (2011). The impact of workplace ostracism in service organizations. International Journal of Hospitality Management, 30(4), 836-844. https://doi.org/10.1016/j. ijhm.2011.01.004 
Lustenberger, D. E., \& Williams, K. D. (2009). Ostracism in organizations. In J. Greenberg \& M. S. Edwards (Eds.), Voice and Silence in Organizations (pp. 245-274). Bingley: Emerald Group Publishing.

Lyons, S. T., Duxbury, L. E., \& Higgins, C. A. (2006). A comparison of the values and commitment of private sector, public sector, and parapublic sector employees. Public Administration Review, 66(4), 605-618. https://doi. org/10.1111/j.1540-6210.2006.00620.x

Lyu, Y., \& Zhu, H. (2017). The predictive effects of workplace ostracism on employee attitudes: A job embeddedness perspective. Journal of Business Ethics, 1, 1-13. https://doi.org/10.1007/s10551-017-3741-x

McArdle, J. J. (1996). Current directions in structural factor analysis. Current Directions in Psychological Science, 5(1), 11-18. https://doi. org/10.1111\%2F1467-8721.ep10772681

McCarthy, J. M., Trougakos, J. P., \& Cheng, B. H. (2016). Are anxious workers less productive workers? It depends on the quality of social exchange. Journal of Applied Psychology, 101(2), 279. https://psycnet. apa.org/doi/10.1037/apl0000044

McCord, M. A., Joseph, D. L., Dhanani, L. Y., \& Beus, J. M. (2018). A meta-analysis of sex and race differences in perceived workplace mistreatment. Journal of Applied Psychology, 103(2), 137. https:// psycnet.apa.org/doi/10.1037/apl0000250

O’Reilly, J., Robinson, S. L., Berdahl, J. L., \& Banki, S. (2014). Is negative attention better than no attention: The comparative effects of ostracism and harassment at work. Organization Science, 26(3), 774-793. https:// doi.org/10.1287/ orsc. 2014.0900

Parker, S. K. (1998). Enhancing role breadth self-efficacy: The roles of job enrichment and other organizational interventions. Journal of Applied Psychology, 83(6), 835-852. https://psycnet.apa.org/doi/10.1037/00219010.83.6.835

Pawar, B. S. (2013). A proposed model of organizational behavior aspects for employee performance and well-being. Applied Research in Quality of Life, 8(3), 339-359. https://doi.org/10.1007/s11482-012-9193-7

Perry, J. L. (2000). Bringing society in: Toward a theory of public-service motivation. Journal of Public Administration Research and Theory, 10(2), 471-488. https://doi.org/10.1093/oxfordjournals.jpart.a024277

Pestonjee, D.M. (1973). Organization Structures and Job Attitudes. Calcutta, India: Minerva Associates.

Powell, G.N., Francesco, A.M., Ling, Y., (2009). Toward culture-sensitive theories of the work-family interface. Journal of Organizational Behavior, 30 (5), 597-616. https://doi.org/10.1002/job.568

Quratulain, S., Khan, A. K., Crawshaw, J. R., Arain, G. A., \& Hameed, I. (2018). A study of employee affective organizational commitment and retention in Pakistan: The roles of psychological contract breach and norms of reciprocity. The International Journal of Human Resource Management, 29(17), 1-28. https://doi.org/10.1080/09585192.2016.1254099 
Rashid, S., \& Rashid, U. (2012). Work motivation differences between public and private sector. American International Journal of Social Science, 1(2), 24-33. http://www.aijssnet.com/journals/Vol_1_No_2_ December_2012/3.pdf

Robinson, S. L., O'Reilly, J., \& Wang, W. (2013). Invisible at work an integrated model of workplace ostracism. Journal of Management, 39(1), 203-231. https://doi.org/10.1177/0149206312466141

Salin, D. (2001). Prevalence and forms of bullying among business professionals: A comparison of two different strategies for measuring bullying. European Journal of Work and Organizational Psychology, 10(4), 425-441. https://doi.org/10.1080/13594320143000771

Sarfraz, M., Qun, W., Sarwar, A., Abdullah, M. I., Imran, M. K., \& Shafique, I. (2019). Mitigating effect of perceived organizational support on stress in the presence of workplace ostracism in the Pakistani nursing sector. Psychology Research and Behavior Management, 12, 839-849. https:// doi.org/10.2147/PRBM.S210794

Schwarzer, R., \& Hallum, S. (2008). Perceived teacher self-efficacy as a predictor of job stress and burnout: Mediation analyses. Applied Psychology, 57(s1), 152-171. https://doi.org/10.1111/j.1464-0597.2008.00359.x

Seggelen-Damen, I. V., \& Dam, K. V. (2016). Self-reflection as a mediator between self-efficacy and well-being. Journal of Managerial Psychology, 31(1), 18-33. https://doi.org/10.1108/JMP-01-2013-0022

Selye, H. (1973). The evolution of the stress concept: The originator of the concept traces its development from the discovery in 1936 of the alarm reactions to modern therapeutic applications of syntoxic and catatoxic hormones. American Scientist, 61(6), 692-699. https://psycnet.apa.org/ record/1974-10586-001

Smith, M. P., \& Nock, S. L. (1980). Social class and the quality of work life in public and private organizations. Journal of Social Issues, 36(4), 59-75. https://doi.org/10.1111/j.1540-4560.1980.tb02637.x

Steinbauer, R., Renn, R. W., Chen, H. S., \& Rhew, N. (2018). Workplace ostracism, self-regulation, and job performance: Moderating role of intrinsic work motivation. The Journal of Social Psychology, 158 (6), 1-17. https://doi.org/10.1080/00224545.2018.1424110

Tehrani, N. (2004). Bullying: a source of chronic post-traumatic stress? British Journal of Guidance \& Counselling, 32(3), 357-366. https://doi.org/10.1 080/03069880410001727567

Tepper, B. J. (2000). Consequences of abusive supervision. Academy of Management Journal, 43(2), 178-190. https://doi.org/10.5465/1556375

Vartia, M. (1996). The sources of bullying-psychological work environment and organizational climate. European Journal of Work and Organizational Psychology, 5(2), 203-214. https://doi.org/10.1080/13594329608414855

Vartia, M., \& Hyyti, J. (2002). Gender differences in workplace bullying among prison officers. European Journal of Work 
and Organizational Psychology, 11(1), 113-126. https://doi. org/10.1080/13594320143000870

Williams, K. D. (1997). Social ostracism. In R. M. Kowalski (Ed.), Aversive Interpersonal Behaviors (pp. 133-170). New York, NY: Plenum. https:// doi.org/10.1007/978-1-4757-9354-3_7

Williams, K. D. (2001). Ostracism: The Power of Silence. New York, NY: Guilford. Williams, K. D. (2007). Ostracism. Annual Review of Psychology, 58(1), 425452. https://doi.org/10.1146/annurev. psych.58.110405.085641

Williams, K. D., Govan, C. L., Croker, V., Tynan, D., Cruickshank, M. \& Lam, A. (2002). Investigations into differences between social and cyberostracism. Group Dynamics: Theory, Research, and Practice, 6, 65-77. https://doi. org/10.1037/1089-2699.6.1.65

Wu, L. Z., Yim, F. H. K., Kwan, H. K., \& Zhang, X. (2012). Coping with workplace ostracism: The roles of ingratiation and political skill in employee psychological distress. Journal of Management Studies, 49(1), 178-199. https://doi.org/10.1111/j.1467-6486.2011.01017.x

Xu, E., Huang, X., \& Robinson, S. L. (2017). When self-view is at stake: Responses to ostracism through the lens of self-verification theory. Journal of Management, 43(7), 2281-2302. https://doi. org/10.1177\%2F0149206314567779

Yang, K.S. (1993). Chinese social orientation: An integrative analysis. In L.Y. Cheng, F.M.C. Cheung, \& C.-N. Chen (Eds.), Psychotherapy for the Chinese: Selected Papers from the First International Conference. Hong Kong: Chinese University of Hong Kong.

Yeo, G. B., \& Neal, A. (2006). An examination of the dynamic relationship between self-efficacy and performance across levels of analysis and levels of specificity. Journal of Applied Psychology, 91(5), 1088-1101. https://psycnet.apa.org/doi/10.1037/0021-9010.91.5.1088

Zellars, K. L., Tepper, B. J., \& Duffy, M. K. (2002). Abusive supervision and subordinates' organizational citizenship behavior. Journal of Applied Psychology, 87(6), 1068-1076. https://psycnet.apa.org/ record/2003-01068-007

Zhao, H., Peng, Z., \& Sheard, G. (2013). Workplace ostracism and hospitality employees' counterproductive work behaviors: The joint moderating effects of proactive personality and political skill. International Journal of Hospitality Management, 33, 219-227. https://doi.org/10.1016/j. ijhm.2012.08.006

Zhou, J., \& George, J. M. (2001). When job satisfaction leads to creativity: Encouraging the expression of voice. Academy of Management Journal, 44(4), 682-696. https://doi.org/10.5465/3069410

Zhou, X., Ma, J., \& Dong, X. (2018). Empowering supervision and service sabotage: A moderated mediation model based on conservation of resources theory. Tourism Management, 64, 170-187. https://doi. org/10.1016/j.tourman.2017.06.016 
Zhu, H., Lyu, Y., Deng, X., \& Ye, Y. (2017). Workplace ostracism and proactive customer service performance: A conservation of resources perspective. International Journal of Hospitality Management, 64, 6272. https://doi.org/10.1016/j.ijhm.2017.04.004

Appendix: Items in questionnaires

\section{Workplace Ostracism (Ferris, Brown, Berry, \& Lian, 2008a)}

5-point scale; never to very often response format;

In the past 3 months, how often have you felt that:

1) Others ignored you at work.

2) Others left the area when you entered.

3) Your greetings have gone unanswered at work.

4) You involuntarily sat alone in a crowded lunchroom at work.

5) Others avoided you at work.

6) You noticed others would not look at you at work.

7) Others at work shut you out of the conversation.

8) Others refused to talk to you at work.

9) Others at work treated you as if you weren't there.

10) Others at work did not invite you or ask you if you wanted anything when they went out for a coffee break.

\section{Stress (Galinsky, Bond \& Swanberg, 1998)}

5-point scale; never to very often response format

In the past 3 months, how often have you:

1) Felt nervous and stressed

2) Felt emotionally drained from your work

3) Felt burned out or stressed by your work

4) Felt frustrated by your work

5) Found that you could not cope with all the things you had to do

6) Felt tired when you got up in the morning and had to face another day on the job

7) Felt used up at the end of the workday

\section{Self-Efficacy (Chen, Gully \& Eden, 2001)}

5-point scale; agree to disagree format

The degree to which you agree or disagree with the following statements:

1) I will be able to achieve most of the goals that I have set for myself.

2) When facing difficult tasks, I am certain that I will accomplish them.

3) In general, I think that I can obtain outcomes that are important to me.

4) I believe I can succeed at any endeavor to which I set my mind. 
5) I will be able to successfully overcome many challenges.

6) I am confident that I can perform effectively on many different tasks.

7) Compared to other people, I can do most tasks very well.

8) Even when things are tough, I can perform quite well.

\begin{abstract}
Abstrakt
Artykuł ma na celu wyjaśnienie zwiqzku między ostracyzmem w miejscu pracy a stresem, ponieważ ostracyzm jest najbardziej rozpowszechniona formq złego traktowania we wspótczesnych warunkach pracy. Bada również moderujaca rolę poczucia własnej skuteczności pracowników, płci i kultury pracy. Dane zebrano za pomoca ankiety i ustrukturyzowanych kwestionariuszy od pracowników pracujqcych zarówno w bankach sektora publicznego, jak i prywatnego w Pakistanie. Analiza danych została przeprowadzona przy użyciu technik statystycznych, takich jak analiza bootstrapping, test Sobela i analiza regresji. Wyniki badania wskazujq, że ostracyzm w miejscu pracy jest pozytywnie zwiqzany ze stresem; i poczuciem własnej skuteczności pracowników. Płeć i kultura pracy organizacyjnej ma relację moderujqcq. Własna skuteczność łagodziła negatywne skutki ostracyzmu w miejscu pracy w postaci stresu, ponieważ samowystarczalni pracownicy zwykle doświadczaja mniejszego stresu w miejscu pracy. Organizacje muszq wziqć pod uwagę łagodzqcy stres wpływ własnej skuteczności, która jest zasadniczo silna dla zapewnienia akceptowalnego działania, ponieważ złego traktowania i niegrzecznych zachowań nie można uniknqć i można im całkowicie zapobiec w kontekście społecznym współczesnego miejsca pracy. Implikacje i przyszłe kierunki badań sq omawiane w świetle wyników.
\end{abstract}

Słowa kluczowe: ostracyzm w miejscu pracy, stres, własna skuteczność, teoria zasobowa, przemysł bankowy, Pakistan, Pendżab

\title{
Biographical notes
}

Ambreen Sarwar is a Ph.D. scholar, at Comsats University Islamabad, Lahore Campus. She has MS, MBA, and BBA degrees from Virtual University of Pakistan and Islamia University of Bahawalpur respectively. She received Gold Medal for securing the first position in MS and has several publications in international journals. She is expected to get her doctorate degree next year. Her research interests include Organizational Behavior, Human Resource Management, Gender Diversity, and Social Theories.

Muhammad Ibrahim Abdullah is working as an assistant professor at COMSATS University, Islamabad, Pakistan. He is an HEC Approved Ph.D. Supervisor. He holds a Ph.D. degree in Enterprise Management from Chongqing University. Dr. Ibrahim has published several papers in international and national journals. His area of research includes Marketing, Strategic Management, CSR, E-Commerce, and Consumer Behavior. 
Dr. Muddassar Sarfraz is a Postdoctoral Fellow at the Department of Management and HR, Business School of Hohai University, Nanjing, PR China. He has obtained a Ph.D. in Management Sciences and Engineering, Master of Business Administration (IMBA), Master of Business Administration (HR) and a Bachelor in Economics from Bahauddin Zakariya University. He has published more than 40 research articles in $\mathrm{SSCl}, \mathrm{E}-\mathrm{SCI}-\mathrm{ISI}$ indexed journals and conference proceedings. He has worked as a researcher and lecturer in various institutes and delivered lecturers on Business Research Methods, Organizational Management, Human Resource Management, Organizational Behavior, and Project Management. His research area focuses on Corporate Social Responsibility, Human Resource Management, Strategic Management, and Business Management.

Muhammad Kashif Imran is a Ph.D. scholar at The Islamia University of Bahawalpur. Currently, he is also working in the National Bank of Pakistan as a senior administrator. He has a wide range of publications in national and international impact factor journals under his belt. His research interests include leadership, change management, knowledge management, and organizational behavior. 
